\title{
Current and prospective applications of exosomal microRNAs in pulmonary fibrosis (Review)
}

\author{
TAO YANG ${ }^{1,2}$, JIAN WANG $^{1}$, JIAYING ZHAO $^{3}$ and YANG LIU ${ }^{1}$ \\ ${ }^{1}$ Department of Respiratory and Critical Care Medicine, Affiliated People's Hospital of Jiangsu University, \\ Zhenjiang, Jiangsu 212001; ${ }^{2}$ The First Clinical Medical School of Nanjing Medical University, Nanjing, \\ Jiangsu 210029; ${ }^{3}$ School of Medicine, Jiangsu University, Zhenjiang, Jiangsu 212001, P.R. China
}

Received November 3, 2021; Accepted January 7, 2022

DOI: $10.3892 / \mathrm{ijmm} .2022 .5092$

\begin{abstract}
Pulmonary fibrosis (PF) is a chronic, progressive, irreversible and life-threatening lung disease. However, the pathogenesis and molecular mechanisms of this condition remain unclear. Extracellular vesicles (EVs) are structures derived from the plasma membrane, with a diameter ranging from $30 \mathrm{~nm}$ to $5 \mu \mathrm{m}$, that play an important role in cell-to-cell communications in lung disease, particularly between epithelial cells and the pulmonary microenvironment. In particular, exosomes are a type of EV that can deliver cargo molecules, including endogenous proteins, lipids and nucleic acids, such as microRNAs (miRNAs/miRs). These cargo molecules are encapsulated in lipid bilayers through target cell internalization, receptor-ligand interactions or lipid membrane fusion. miRNAs are single-stranded RNA molecules that regulate cell differentiation, proliferation and apoptosis by degrading target mRNAs or inhibiting translation to modulate gene expression. The aim of the present review was to discuss the current knowledge available on exosome biogenesis, composition and isolation methods. The role of miRNAs in the pathogenesis of PF was also reviewed. In addition, emerging diagnostic and therapeutic properties of exosomes and exosomal miRNAs in PF were described, in order to highlight the potential applications of exosomal miRNAs in PF.
\end{abstract}

\section{Contents}

1. Introduction

2. Characteristics, classification and biosynthesis of extracellular vesicles

Correspondence to: Dr Yang Liu or Professor Jian Wang, Department of Respiratory and Critical Care Medicine, Affiliated People's Hospital of Jiangsu University, 8 Dianli Road, Zhenjiang, Jiangsu 212001, P.R. China

E-mail: liuyang1386@163.com

E-mail:wj65812@163.com

Key words: pulmonary fibrosis, extracellular vesicles, exosomes, microRNA, pathogenesis
3. Exosomal microRNAs

4. Role of microRNAs in the pathogenesis of pulmonary fibrosis

5. Role of exosomal microRNAs in pulmonary fibrosis

6. Conclusions and future prospects

\section{Introduction}

Pulmonary fibrosis (PF) is a chronic, aged-related, progressive, irreversible and life-threatening lung disease caused by alveolar epithelial cell injury and apoptosis, epithelial-mesenchymal transition (EMT), fibroblast proliferation, as well as extracellular matrix (ECM) deposition in the interstitial tissue. Idiopathic PF (IPF) is the most common type of PF, and its diagnosis is based on radiographical and/or histopathological patterns typical of usual interstitial pneumonia (1). IPF exhibits a high prevalence among the elderly with a history of smoking, thus increasing morbidity and mortality; there is also currently a lack of effective diagnostic and therapeutic measures (1). The incidence of IPF in North America and Europe (3-9 cases/ 100,000 person-years) is higher than that in South America and East Asia ( $<4$ cases/100,000 person-years) (2). Although the pathogenesis and molecular mechanisms of IPF remain unclear, cell apoptosis and/or senescence, telomere shortening, mitochondrial dysfunction, endoplasmic reticulum stress, oxidant/antioxidant imbalance and immunoregulatory dysfunction may be involved (3-6).

With the US Food and Drug Administration approval of pirfenidone and nintedanib, the treatment of IPF has reached a new plateau, and the majority of patients succumb to respiratory failure within 3-5 years following diagnosis $(7,8)$. The results of a phase-2, double-blind, randomized, placebo-controlled clinical study investigating lebrikizumab (an anti-IL-13 monoclonal antibody) alone or combined with pirfenidone treatment in patients with IPF indicated that this therapeutic strategy may not be sufficient to improve pulmonary function (9). A previous meta-analysis of the use of pirfenidone, nintedanib and pamrevlumab (monoclonal antibody targeting connective tissue growth factor, FG-3109) for the treatment of patients with IPF suggested that pamrevlumab significantly improved pulmonary function and was effective in attenuating the decline in forced vital capacity (10). Thus, it may 
become a potential candidate for IPF treatment for phase-3 clinical trials. In small randomized trials, other drugs, such as pentraxin 2 (11) and GLPPG1690 (12), have also resulted in a slower decline in pulmonary function than the administered placebo (13). Despite these findings, to date, there is no effective treatment available for IPF, at least to the best of our knowledge. All available therapies are only effective for a small number of patients and have severe side-effects, together with a low overall survival rate. Therefore, there is still a need for the development of novel therapies that may provide additional clinical benefits to patients with IPF.

Extracellular vesicles (EVs) are present in body fluids, such as serum, plasma, urine, saliva, sputum, uterine secretions and bronchoalveolar lavage fluid (BALF) (14). EVs, including exosomes, play an important role in cell-to-cell communications, particularly between epithelial cells and the pulmonary microenvironment (14). MicroRNAs (miRNAs/miRs), EVs and/or exosomes may represent potential biomarkers for the diagnosis and prognosis of IPF, as well as therapeutic targets for this disease (15). The present review discusses the current understanding of the role of EVs, particularly that of exosomes and exosomal miRNAs in the pathogenesis of PF and/or IPF. The clinical process of IPF diagnosis and treatment based on exosomes and exosomal miRNAs is also discussed.

\section{Characteristics, classification and biosynthesis of extracellular vesicles}

EVs are structures derived from plasma membranes with diameters ranging from $30 \mathrm{~nm}$ to $5 \mu \mathrm{m}$ and are composed of a phospholipid bilayer (14). EVs were first identified in the late 1960s in cells from mammalian tissue or fluids (16), although they were not named as such until 2011 (17). In the 1980s, EVs were found to be generated either by budding from the plasma membrane or through intracellular pathways, including incorporating multivesicular bodies (MVBs) into the plasma membrane (18).

Depending on their biosynthesis, particle size and biophysical properties, EVs can be classified into four subtypes as follows: Exosomes, microvesicles (MVs) or micropaticles (19) and apoptotic bodies $(20,21)$, as well as smaller-diameter subsets of nanoparticle exomeres $(22,23)$. Different subtypes of EVs can be enriched and broadly separated using different methods, such as ultracentrifugation, ultrafiltration, polymer precipitation, immunoaffinity chromatography, flow cytometry, density gradient centrifugation, microfluidics-based techniques and immunoadsorption (24). Currently, the gold standard for EVs isolation is the ultracentrifugation-linked immunoprecipitation method (25). However, none of these methods can completely purify a specific subpopulation, resulting in preparations that are mixed with other EV subtypes. A membrane affinity spin column can capture nearly $100 \%$ mRNA from EVs without undesired protein-bound extracellular RNA co-precipitate (25). EVs isolation and enrichment is considered a necessary pre-analytical requirement for biomedical research and clinical treatment $(26,27)$. A list of different subtypes of EVs is presented in Table I.

The biosynthesis of exosomes is a progressive endosome-dependent cytological process (28). This process begins with endocytosis and is characterized by invagination of the cell membrane to form an early-sorting endosome; subsequently, the intranuclear soma re-invaginates and sheds to form small intraluminal vesicles (ILVs). The formation of ILVs is followed by the generation of late-sorting endosomes, termed MVBs. When MVBs coalesce into the cell membrane, ILVs are released into the extracellular space as exosomes (29).

Exosome biosynthesis and secretion can be triggered by different mechanisms, such as endosomal sorting complex-dependent pathways and ceramide-dependent pathways required for transport (30). The former are mediated by the endosomal sorting complex required for transport (ESCRT). ESCRT is a family of proteins that includes ESCRT-0, -I, -II and -III (31). These proteins bind to MVB membrane-associated proteins and regulate the targeted transport of cellular cargo molecules and the formation of ILVs (32). Also involved in the formation of MVBs are tumor susceptibility gene 101 and other ESCRT cofactors, such as ALG-2 interacting protein $\mathrm{X}$ (33) and vacuolar protein sorting-associated protein 4 (34). In addition, some ESCRT-associated proteins can promote the secretion of exosomes independently of ubiquitination. The post-translational binding of Sentrin/small ubiquitin-like modifiers (SUMO) to proteins plays a vital role in mediating ESCRT-dependent EV biosynthesis $(35,36)$.

The ESCRT-independent mechanism of exosome formation was first described in the study by Trajkovic et al (29), reporting that intracellular ceramide was deposited with the depletion of neutral sphingomyelinase, causing small craft-based microdomains to fuse into larger domains to induce exosomes budding. Subsequently, lipid raft microdomains in exosomal membranes (37), tetraspanins (38), and CD63 (39), CD82 and CD9 (40) were found to be involved in ESCRT-independent pathways.

When exosomes were first discovered, they were considered as cellular waste products, and their functions were unclear. However, several studies have demonstrated that exosomes are important mediators of intercellular communication that can transport endogenous proteins (41), lipids (42) and nucleic acids (43) encapsulated in lipid bilayers through target cell internalization, receptor-ligand interactions or lipid membrane fusion (44). The components of exosomes of different cellular origins have a common protein composition (45).

Exosomes contain various proteins, such as transmembrane proteins (CD9, CD63, CD81 and CD82), heat shock proteins involved in signal transduction (such as HSP60, HSP70 and HSP90), the factor-associated suicide ligand (FasL) regulating the immune response, cytokines such as TGF- $\beta$, interferon- $\gamma$ and TNF- $\alpha$, as well as cytoskeletal proteins (actin and microtubulin) (46). CD9, CD63, CD81 and HSP70 are also used as biomarkers to identify exosomes (40). The lipid components are mostly sphingolipids, ceramides, phosphoglycerides, phosphatidylserine and cholesterol (47). Exosomes also contain various nucleic acids, including DNA, mRNAs, miRNAs, long non-coding RNAs (lncRNAs) and fragmented mRNAs (44).

\section{Exosomal microRNAs}

miRNAs are a class of highly conserved endogenous small non-coding RNAs widely distributed in plants, animals and DNA viruses. They are single-stranded RNA molecules consisting of 19-25 nucleotides (average length of 
Table I. Subtypes of EVs.

\begin{tabular}{|c|c|c|c|c|c|}
\hline Subtypes & Size & Biomarker & Contents & Biosynthesis pathway & (Refs.) \\
\hline $\begin{array}{l}\text { Apoptotic bodies } \\
\text { (Large EVs) }\end{array}$ & $1-5 \mu \mathrm{m}$ & $\begin{array}{l}\text { Annexin, } \\
\text { histone } \mathrm{H} 3,\end{array}$ & $\begin{array}{l}\text { Nucleoprotein, Golgi, } \\
\text { endoplasmic reticulum, } \\
\text { other cellular organelles }\end{array}$ & Apoptosis pathway & $(20,21,24)$ \\
\hline $\begin{array}{l}\text { Microvesicles } \\
\text { (Medium EVs) }\end{array}$ & $100-1,000 \mathrm{~nm}$ & $\begin{array}{l}\text { Integrin, } \\
\text { selectin, } \\
\text { annexin A1, } \\
\text { CD40L }\end{array}$ & RNA, cytoplasmic protein & $\begin{array}{l}\text { Budding from the plasma } \\
\text { membranes pathway }\end{array}$ & $(19,20,21,25)$ \\
\hline $\begin{array}{l}\text { Exosomes, } \\
\text { (Small EVs) }\end{array}$ & $40-120 \mathrm{~nm}$ & $\begin{array}{l}\text { CD9, CD63, } \\
\text { CD81, } \\
\text { HSP70, Alix, } \\
\text { TSG101 }\end{array}$ & $\begin{array}{l}\text { DNA, RNA, cytoplasmic } \\
\text { protein, membrane protein }\end{array}$ & $\begin{array}{l}\text { Endocytosis of cell } \\
\text { membrane forming } \\
\text { MVBs pathway }\end{array}$ & $(20,21,24,27,32,33)$ \\
\hline $\begin{array}{l}\text { Exomeres } \\
\text { (Nanoparticles EVs) }\end{array}$ & $35-50 \mathrm{~nm}$ & $\begin{array}{l}\text { HSP90, } \\
\text { HSPA13 }\end{array}$ & $\begin{array}{l}\text { DNA, RNA, protein, } \\
\text { enzymes, lipid }\end{array}$ & None & $(22,23)$ \\
\hline
\end{tabular}

EVs, extracellular vesicles; HSP, heat shock protein; TSG101, tumor susceptibility gene101 protein; Alix, ALG-2 interacting protein; HSPA13, heat shock protein family A (Hsp70) member 13.

22 nucleotides), which regulate cell differentiation, proliferation and apoptosis by degrading the target mRNAs or inhibiting translation to regulate gene expression $(48,49)$. In 2007, Valadi et al (50) demonstrated for the first time that both mouse and human mast cell exosomes contained mRNAs and miRNAs that could be transferred to and mediate physiological functions in the recipient cells. Subsequently, other studies confirmed the existence of several other non-coding RNA species in exosomes $(51,52)$.

The initial transcription products of miRNAs are primary transcripts (pri-miRNAs) with a hairpin structure. Ribonuclease III releases the hairpin-shaped pri-miRNAs to form precursor miRNAs (pre-miRNAs) with a stem-looped structure (48). The endonuclease Dicer removes the pre-miRNA $3^{\prime}$ and 5' loop structures to form the miRNA duplex. The miRNA binds to members of the argonaute RISC catalytic component (Ago) protein family, discard the follower strand, with the guide strand complementing the miRNA-induced silencing complex to produce mature miRNA $(53,54)$. Through the exchange of material between cells, exosomes deliver intronic miRNA molecules to the cytoplasm of target cells that specifically bind to the $3^{\prime}$ untranslated region of mRNA transcripts to regulate the expression of target genes.

Accumulating evidence suggests that miRNAs are not randomly integrated into exosomes. Of all the RNA types, miRNAs are more prevalent in exosomes than in the cells from which they originate (55). In a previous study involving the analysis of exosomes secreted by different cell lines, some miRNA subgroups, such as miR-150, miR-142-3p and miR-451, were found to preferentially localize into exosomes (56). For instance, miRNA-574-5p has been shown to be only expressed in lung adenocarcinoma cells, but not in squamous cell carcinoma, suggesting a cell-specific response to exosomal miRNAs, which may be due to the unique composition of tetraspanin which strongly influences EV uptake (57). Exosomes internalize miRNAs through various mechanisms, and different RNA subpopulations bind to different exosome-targeted RNA-binding proteins (RBPs). For example, the miRNA-associated effector protein, Ago2, has been reported as an exosomal intron in several cell types. In addition, it has been found that exosomal miRNAs and Ago2 released from cancer tissue play an essential role in the metastasis of breast cancer (58). The contents of exosomal miRNAs depend to some extent on the abundance of exosomal Ago2, and exosomes are also commonly enriched in miRNAs containing the GGAG sequence (59). miRNAs are accompanied by the extensive binding of the RBP heterogeneous nuclear ribonucleoprotein A2B1 (hnRNPA2B1). These findings identify hnRNPA2B1 as a vital player in miRNA sorting into exosomes. In addition, SUMOylated hnRNP effectively controls the integration of sorting-specific miRNAs into exosomes (59). Another study has suggested that the RBP synaptotagmin-binding cytoplasmic RNA-interacting protein (also known as hnRNPQ or NSAP1), directly binds to specific exosomal miRNA molecules and shares a common extra-seed sequences (EXO (exosomes) motif), thus mediating miRNA sorting into exosomes in hepatocytes (60).

\section{Role of microRNAs in the pathogenesis of pulmonary fibrosis}

miRNAs in pulmonary diseases. To date, >2,500 miRNA molecules have been identified, and previous research has examined this RNA type in pulmonary diseases (61). For example, in the plasma of patients with chronic obstructive pulmonary disease (COPD), the expression levels of circulating hsa-miR-19b-3p and miR-320c were shown to be increased, while those of hsa-miR-125b-5p were downregulated; these molecules may represent promising biomarkers for the diagnosis of COPD (62). Through the p38-MAPK-c-Myc signaling pathway, oxidative stress can induce the expression of miR-494-3p, which can directly bind to sirtuin (SIRT)3 and 
reduce its expression, thereby increasing cell senescence and promoting the progression of COPD (63).

In asthmatic patients, the expression of let-7a, and miR-21, $-133 a,-155,-328$ and -1248 in exhaled breath condensates has been shown to be significantly lower than in healthy individuals (64). Serum miRNA expression is age-dependent and is associated with clinical asthma features and systemic inflammation, suggesting that miRNAs play differential roles in the pathogenesis of asthma in patients from different age groups (65).

As previously demonstrated in a systematic review, in lung cancer, blood-derived miR-20a, -10b, -150 and -223 are excellent diagnostic biomarkers for non-small cell lung cancer, whereas miR-205 is specific for squamous cell carcinoma (66). miR-34a, -93, -106b, -181a, -193a-3p and -375 may serve as theragnostic biomarker candidates to checkpoint inhibitor treatments (66). Moreover, miR-21, -25, -27b, -19b, -125b, -146a and -210 can predict responsiveness to platinum-based treatment (66). The results of exosomal RNA sequencing in patients with lung cancer suggested that adenocarcinoma-specific, exosomal miR-181-5p, -30a-3p, -30e-3p and -361-5p, as well as squamous carcinoma-specific exosomal miR-10b-5p, $-15 b-5 p$ and $-320 \mathrm{~b}$ levels were differentially expressed, and these miRNA molecules may be valid candidates for the development of highly sensitive and non-invasive biological markers for early diagnosis (67).

Yang et al (68) analyzed human serum miRNAs from healthy volunteers and patients with rapidly and slowly progressing IPF. The results suggested that 47 miRNA molecules were characteristically expressed in patients with IPF, of which 21 were upregulated and 26 were downregulated. Moreover, the results from reverse transcription-quantitative PCR revealed that the expression of miR-21, miR-199a-5p and miR-200c in patients with IPF was markedly higher than that in healthy volunteers, while the miR-31, let-7a and let-7d expression levels were significantly lower. Thus, miRNA molecules found in serum, BALF, sputum and other body fluids may have the advantages of disease-specific expression, easy detection and quantification. They may become useful diagnostic biomarkers for lung diseases (69).

miRNAs and alveolar epithelial cell apoptosis. When type-I alveolar epithelial cells are injured, type-II alveolar epithelial cells (AEC-IIs) proliferate to promote lung tissue repair (70). AEC-II apoptosis is a key determinant in the initiation and development of IPF. miR-30a has been shown to be significantly downregulated in a murine model of bleomycin-induced lung fibrosis (71). Furthermore, miR-30a overexpression has been shown to inhibit AEC-II apoptosis by dampening mitochondrial fission through dynamin-related protein-1. miR-29 is downregulated in IPF lungs, which promotes apoptosis resistance (72). TGF- $\beta$ inhibits the expression of miR-29c and Fas receptors, causing AEC-II apoptosis and fibrosis. In aged mice, miR-34a upregulation has been found to accelerate lung epithelial cell senescence, apoptosis and mitochondrial damage, resulting in epithelial cell dysfunction and increased lung fibrosis (73).

p53 is an important cellular senescence marker (74). Shetty et al (73) suggested that both miR-34a and p53 acetylation expression were increased in different factor-induced lung epithelium injury and IPF models, which was accompanied by the decreased expression of SIRT1, an NAD ${ }^{+}$-dependent histone deacetylase that deacetylates the lysine residues of various proteins. It was also found that the inhibition of miR-34a upregulated SIRT1, and the overexpression of SIRT1 reduced the acetylation levels of p53, thus reducing the apoptosis of lung epithelial cells (73). Therefore, the p53-miR-34a/SIRT1 pathway may be a potential target for the treatment of IPF via the inhibition of epithelial cell apoptosis (Fig. 1).

miRNAs and EMT. EMT is a dynamic and flexible biological process, during which epithelial cells lose their cell polarity and basilar membrane adhesion, change their shape with marked cytoskeletal alterations and acquire the ability to migrate (75). EMT impairs re-epithelialization, resulting in abnormal tissue repair, inflammatory cell infiltration, fibroblast proliferation, ECM deposition and scarring (76). This process is important in $\mathrm{PF}$ and also serves essential roles in implantation and gastrulation of the embryo, inflammatory and cancer metastasis (76). Silica dynamically downregulates miR-29b expression in RLE-6TN cells, which regulates mesenchymal-epithelial transition (MET). In vivo, the administration of miR-29b to mice has been shown to significantly restrain silica-induced EMT, prevent lung fibrosis and improve lung function (77). miR-34a expression is significantly downregulated in silica-induced $\mathrm{PF}$ and TGF- $\beta$-treated A549 cells in vitro (78). In addition, miR-34a can inhibit EMT by suppressing the TGF- $\beta$ signaling pathway and reducing the expression of SMAD4 in PF. Odd-skipped related transcription factor 1 (OSR1) is a potential target for miR-451a; indeed, miR-451a inhibits the expression of OSR1 and impairs EMT in vitro (79). A previous review article reported the inhibition of EMT by miR-7, -185, $-186,-200$, and -448 , while miR-21 promoted EMT in PF (80). Therefore, miRNAs may be a potential target for the treatment of PF by inhibiting EMT.

miRNAs and myofibroblast differentiation. IPF progresses primarily through the action of myofibroblasts in the lungs. TGF- $\beta 1$ is a profibrogenic cytokine that induces the differentiation of lung myofibroblasts, and emerging evidence has demonstrated TGF- $\beta 1$ can regulate miRNA expression in IPF (81). Previous studies have demonstrated that TGF- $\beta 1$ significantly upregulates miR-133a expression in a time- and concentration-dependent manner (82). Moreover, in a previous study, TGF- $\beta 1$-induced myofibroblast differentiation was shown to be inhibited by miR-133a and to be promoted by miR-133a inhibitors (82). In mice, the transfection of miR-133a into lung tissue was also found to improve bleomycin-induced lung fibrosis (82). In another study, lncRNA H19 served as a miRNA sponge for let-7a, which mediated arsenite-induced M2 polarization of macrophages and c-Myc-induced myofibroblast differentiation in PF (83). Several other miRNA molecules can aggravate or attenuate PF by promoting or inhibiting myofibroblast differentiation, such as miR-21 (84), miR-424 (85), miR-497-5p (86) and miR-877-3p (87).

miRNAs and ECM deposition. Several growth factors, cytokines, chemokines and matrix metalloproteinases (MMPs) are involved in the development of IPF. MMPs can disrupt the basilar lamina, allowing lung fibroblasts to enter the 


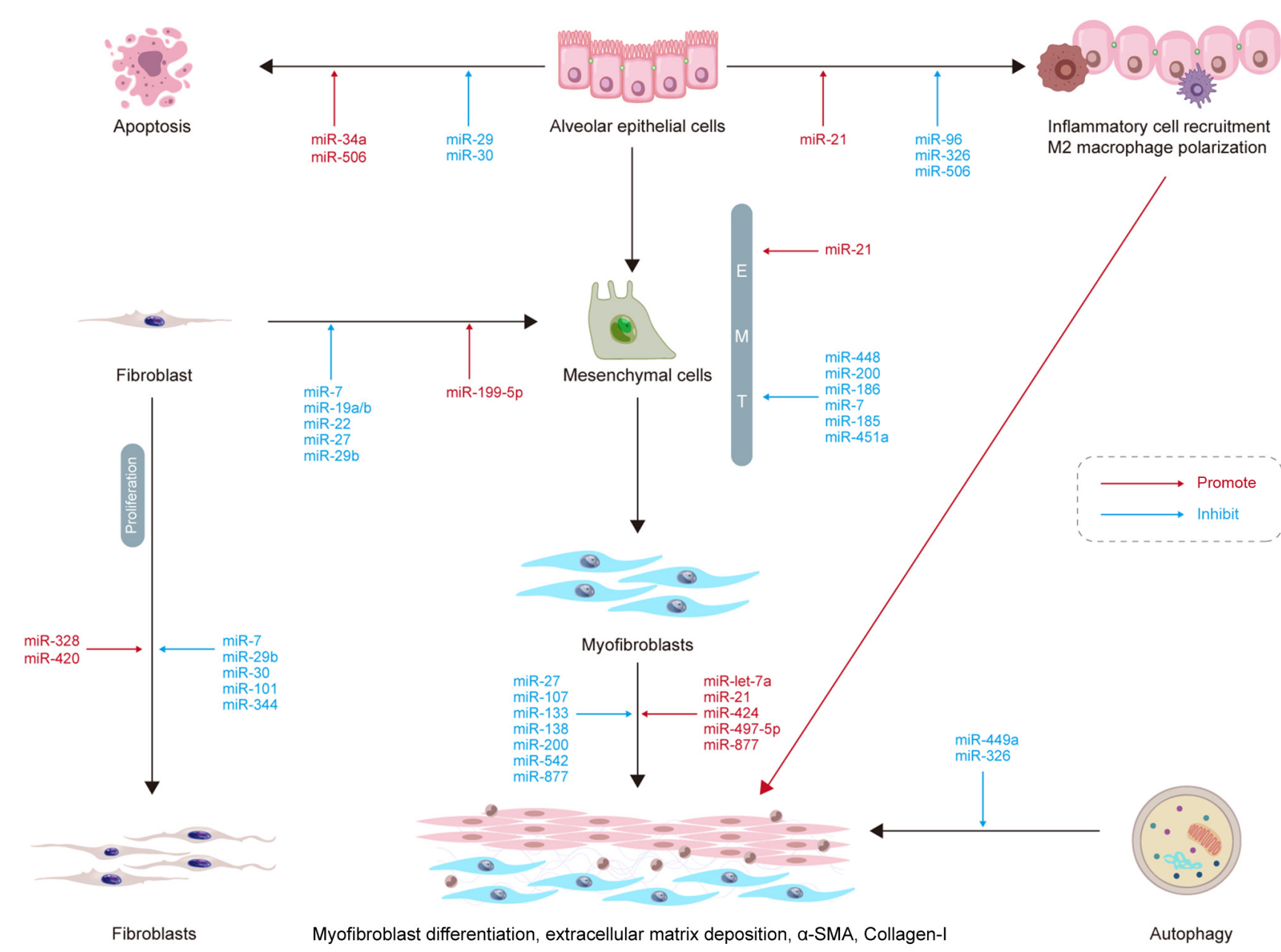

Figure 1. Role of miRNAs in the process of pulmonary fibrosis. Following pulmonary damage, alveolar epithelial cells undergo apoptosis and recruit inflammatory cells, including the polarization of M2 macrophages. Alveolar epithelial cells differentiate into myofibroblasts via epithelial-mesenchymal transition. Fibroblasts proliferate and differentiate into myofibroblasts; autophagy is involved in fibrosis and plays a role in the degradation of the extracellular matrix, which eventually leads to deposition of extracellular matrix components and to the development of pulmonary fibrosis. miRNAs illustrated in red color facilitate this process, whereas those in blue color inhibit this process.

alveolar space where they proliferate and produce collagen and other ECM components, resulting in abnormal ECM deposition and further promoting PF development (88). Previous research has suggested that the lncRNA miR155 host gene (miR155HG) is upregulated in PF tissue and normal human primary lung fibroblasts (NHLFs) stimulated with TGF- $\beta 1$ (89). Moreover, miR155HG binds directly to miR-627 inhibits miR-627 expression (89). Thus, the overexpression of miR-627 reduces TGF-1-induced changes in NHLFs and significantly reverses the excessive EMC deposition caused by overexpression of miR155HG. Microvascular pericytes are the source of excess ECM protein produced by myofibroblasts, contributing to PF (90). miR-107 expression has been shown to be reduced in clinical or experimental mouse PF tissue samples and exosomes by PF-derived microvascular endothelial cells (90). The anti-fibrotic effect of miR-107 is mediated by the inhibition of the hypoxia inducible factor $1 \alpha$ $($ HIF-1 $\alpha$ )/Notch $1 /$ platelet-derived growth factor receptor $\beta$ (PDGFR $\beta$ )/Yes 1-associated transcriptional regulator/Twist1 signaling pathway. Indeed, miR-107 targets HIF-1 $\alpha$ mRNA directly, and HIF-1 $\alpha$ directly activates the transcription of Notch1 and PDGFR $\beta$, thereby inhibiting ECM deposition (90). ECM deposition is also inhibited by other miRNA molecules, such as miR-133, $-138,-200$ and -542 and promoted by miR-497 and $-877(80)$.

miRNAs and fibroblast proliferation and differentiation. In PF, fibroblasts differentiate into myofibroblasts, which may secrete a greater amount ECM and collagen components than fibroblasts, thus increasing ECM deposition in the lung interstitium and aggravating PF; on the other hand, the abnormal activation and proliferation of lung fibroblasts are also crucial for the onset and progression of PF (91). miRNAs have been shown to play a role in fibroblast proliferation and differentiation. For instance, miR-7 expression has been found to be significantly downregulated in polymyositis-associated interstitial lung diseases, while the components of neutrophil extracellular trap components, myeloperoxidase and histone 3 , promote the proliferation and differentiation of lung fibroblasts (92). Another study revealed that miR-7 attenuated the proliferation and differentiation of fibroblasts by inhibiting SMAD2 expression (92). In vitro, miR-19a, $-19 \mathrm{~b}$ and $-26 \mathrm{~b}$ have been shown to inhibit connective tissue growth factor expression in the WI-38 human embryonic lung fibroblast cell line. In vivo, the expression of miR-19a, $-19 \mathrm{~b}$ and $-26 \mathrm{~b}$ has been shown to be downregulated in the murine bleomycin-induced 
PF model, and these miRNA molecules can ameliorate PF by inhibiting fibroblast differentiation and activating the MAPK pathway (93). However, the Snail/miR-199a-5p axis promotes endothelial-mesenchymal transition in irradiated endothelial cells, which promotes fibroblast differentiation into myofibroblasts (94). Other miRNA molecules, such as miR-30, -101 and -344 , can inhibit fibrosis by suppressing fibroblast proliferation, whereas miR-328 and -420 exert the opposite effect (80). Therefore, regulating miRNA expression may represent a novel therapeutic strategy to prevent or even partially reverse the development of IPF.

miRNAs and inflammation. Inflammation is related to the onset of PF. However, the role of the inflammatory response in the development of $\mathrm{PF}$ remains under debate, as anti-inflammatory treatments are ineffective in the treatment of IPF (95). Nevertheless, there is evidence to suggest that inflammatory cells play a significant role in regulating the microenvironment following IPF through innate and adaptive immune responses (96). In a previous study, the downregulation of miR-506 was observed following during lipopolysaccharide-induced $\mathrm{PF}$ in rats with acute respiratory distress syndrome; both in vivo and in vitro, miR-506 induced apoptosis and reduced inflammation. In addition, miR-506 was shown to target the 3'-UTR of NF- $\mathrm{BB} / \mathrm{p} 65$ to reduce its expression, and p65 inhibition significantly reduced lung fibrosis and inflammation (97). Thus, miR-506 may regulate apoptosis and inflammation, as well as lung fibrosis.

It has been shown that there is a positive correlation between the expression of forkhead transcription factor O (FOXO) 3a and the activation of NOD-like receptor protein 3 (NLRP3) inflammasome. FOXO3a is one of the targets of miR-96 (98). miR-96 expression is reduced in carbon black nanoparticle (CBNP)-induced bronchial epithelial cells, which is accompanied by a significant increase in the expression of FOXO3a, the NLRP3 inflammasome and $\alpha$-smooth muscle actin ( $\alpha$-SMA). These effects were suppressed following miR-96 transfection, suggesting that miR-96 silencing can lead to an upregulation of FOXO3a, thereby promoting the activation of NLRP3 inflammasome and aggravating CBNP-induced PF (98). Another study also found that miR-21 expression was significantly elevated in a nano-nickel-induced murine model of lung injury and fibrosis and that miR-21 silencing inhibited TGF- $\beta 1$ signaling and alleviated PF (99).

miRNAs and autophagy. Autophagic cell death, also known as type-II programmed cell death, is a biological phenomenon that that eliminates the cellular by-products of eukaryotic cells (100). Autophagy requires the formation of autophagosomes, which are double-membrane structures containing isolated cytoplasmic material that eventually fuse with lysosomes to form autophagic lysosomes for content degradation (101). Autophagy may be involved in fibrosis and plays a vital role in the degradation of the ECM in fibrotic diseases (102). Xu et al (103) suggested that the expression of miR-326 in the fibrotic lung tissue of mice treated with silica was downregulated, whereas miR-326 upregulation could attenuate silica-induced lung fibrosis in vivo. Tumor necrosis factor superfamily member 14 (TNFSF14) and polypyrimidine tract binding protein 1 (PTBP1) have been identified as the targets of miR-326 (103). Thus, the overexpression of miR-326 can inhibit silica-induced PF by inhibiting inflammation and promoting autophagy by targeting TNFSF14 and PTBP1 (103). miR-499a has also been shown to significantly reduce PF and promote autophagy in vivo and in vitro (104).

\section{Role of exosomal microRNAs in pulmonary fibrosis}

$B A L F$-derived exosomal miRNAs. BALF is the fluid that is collected through a flexible bronchoscope during bronchoalveolar lavage (105). This fluid is mainly composed of cells (including resident intrinsic trachea and alveolar cells, as well as recruited inflammatory cells), but also contains EVs or exosomes (106). It is an important diagnostic material that provides information about the immunological, infectious and inflammatory processes occurring in the alveoli (105). BALF contains a large number of EVs. Indeed, a previous study identified 1.8-3.8 $\times 10^{8} \mathrm{EV}$-like particles per milliliter of BALF using nanoparticle tracking analysis (107). Another study assessed the miRNA expression patterns in BALF exosomes from elderly patients with IPF, the high-throughput quantification of miRNA expression using a microarray revealed that miR-125b, -128, -21, -100, -140-3p and -374b expression was increased in patients with IPF, whereas that of let-7d, miR-103, -26 and $-30 a-5 p$ expression was reduced. Furthermore, the overexpression of miR-30a-5p, a miRNA that targets TGF- $\beta$ activated kinase 1/MAP3K7-binding protein 3 (TAB3), was shown to inhibit the expression of TAB3, thus delaying the occurrence of PF (108). miR-145a can suppress EMT by inhibiting the expression of OSR1 in vitro. In a PF mouse model, the expression of miR-145a has been shown to be significantly decreased in BALF-derived EVs, whereas the expression of OSR 1 was increased in PF tissue. The transfection of miR-451a induces autocrine anti-fibrotic effects by downregulating OSR1 (79). Zhu et al (109) found that miR-204-5p was markedly upregulated in BALF-derived exosomes of rats with PF and that BALF-derived exosomal miR-204-5p promoted the progression of the PF by inhibiting autophagy and targeting the AP1S2 gene in vivo and in vitro. A list of exosomal miRNAs involved in PF is presented in Table II.

Differential miRNA expression profiles between patients with IPF and healthy controls may represent a minimally invasive biomarker for IPF screening and diagnosis. BALF-derived exosomal miRNAs may become more practical and reliable biomarkers than invasive lung tissue biopsies.

Sputum-derived exosomal miRNAs. Although BALF analysis is the most commonly used technique for the assessment IPF, induced sputum has been regarded as a safer and less invasive method and has been shown to be clinically valuable for respiratory diseases $(110,111)$. Previous research has demonstrated that the expression and production of proteins, such as insulin-like growth factor binding protein 2, IL-8 and MMP-7 in the sputum of patients with IPF is significantly increased, which may be related to the disease (112). Njock et al (113) conducted an miRNA quantitative PCR array analysis to detect the miRNA expression profile of sputum-derived exosomes in patients with IPF and healthy subjects. The results suggested that 21 miRNA molecules were differentially expressed (seven were unregulated and 14 were downregulated) in IPF. 
Table II. Exosomal-miRNAs in pulmonary fibrosis.

\begin{tabular}{|c|c|c|c|}
\hline & Origin & Exsomal miRNAs & (Refs.) \\
\hline \multirow[t]{3}{*}{ Diagnosis } & BALF & $\begin{array}{l}\text { miR-125b, miR-128, miR-21, miR-100, miR-140-3p, miR-374b, let 7d, } \\
\text { miR-103, miR-26, miR-30a-5p, miR-145a, miR-204-5p }\end{array}$ & $(79,108,109,118)$ \\
\hline & Sputum & $\begin{array}{l}\operatorname{miR}-33 a-5 p, \text { miR-142-3p, miR-192-5, let-7d-5p, miR-26a-5p, } \\
\text { miR-29b-3p, miR-423-3p, miR-142-3p }\end{array}$ & $(113,125)$ \\
\hline & Blood & $\begin{array}{l}\text { miR-141, miR-7, miR-21-5p, miR-16, miR-21, miR-26a, miR-210, let-7d, } \\
\text { miR-18, miR-142-3p }\end{array}$ & $(116-118,125)$ \\
\hline \multirow[t]{6}{*}{ Treatment } & Blood & miR-22, miR-16, & $(119,120)$ \\
\hline & Macrophages & miR-328, miR-142-3p & $(123,125)$ \\
\hline & BMSCs & miR-29b-3p, miR-186 & $(130,132)$ \\
\hline & EnCs & miR-223, miR-27b-3p & $(135)$ \\
\hline & LSCs & miR-99a-5p, hsa-miR-100-5p, miR-30a-3p & $(136)$ \\
\hline & HBECs & miR-16, miR-26a, miR-26b, miR-141, miR-148a, miR-200a & $(137)$ \\
\hline
\end{tabular}

BALF, bronchial alveolar lavage fluid; BMSCs, bone marrow-derived mesenchymal stem cells; EnCs, vascular endothelial cells; LSCs, lung spheroid cells; HBECs, human bronchial epithelial cells.

To assess whether specific abnormally expressed miRNA molecules were related to the pathophysiology of the disease, they examined seven abnormally expressed miRNA molecules (three upregulated miRNA molecules, including miR-33a-5p, $-142-3 p$ and -192-5; four downregulated, including let-7d-5p, miR-26a-5p, -29b-3p and -423-3p) using the ingenuity pathway analysis tool. Functional annotation was used to predict their potential role in the initiation and progression of IPF. They further validated three miRNA molecules (miR-142-3p, miR-33a-5p and let-7d-5p) in an independent cohort from 10 patients with IPF and 8 healthy subjects. Of note, miR-142-3p expression was negatively correlated with the carbon monoxide/alveolar volume, while that of let-7d-5p was positively correlated, suggesting that exosomal miRNAs in the sputum may be associated with the severity of PF (113). Thus, the study of sputum-derived exosomal miRNAs in patients with IPF may help to validate miRNAs previously identified from other samples (such as serum, plasma, BALF and saliva), as well as identify novel miRNAs with potential functions in IPF progression. This, in turn, this may provide insight into the role of sputum-derived exosomal miRNA in the pathogenesis of IPF. In addition, validating sputum exosomal miRNAs as biomarkers of IPF to predict disease severity may pave the way for the development of novel therapeutic approaches for this disease.

Blood-derived exosomal miRNAs. Clinically, EVs can be found and isolated from the majority of biological fluids, although blood and BALF are the most well-characterized sources of EVs (114). Increasing evidence has indicated that exosomes play a cardinal role in intercellular communication by delivering their shipments to target cells in the lungs (such as miRNAs). It has been suggested that exosomes and exosomal miRNAs may eventually be used for the pathogenesis, diagnosis and treatment of pulmonary diseases (115).

As previously demonstrated, compared with healthy subjects, the levels of the anti-fibrotic miRNA, miR-141, are significantly decreased in serum exosomal miRNAs isolated from patients with IPF, whereas those of the fibrogenic miR-7 are increased, resulting in ECM deposition (116). In addition, miR-7 upregulation is associated with the radiologically and physiologically defined disease burden.

In a previous study, in a murine model of PF, miR-21-5p expression was found to be upregulated in serum EVs. In addition, miR-21-5p levels were measured in serum EVs after accounting for differences in serum EV amounts across patients with IPF. Kaplan-Meier analysis revealed that individuals with high blood EV miR-21-5p levels had a poorer survival rate than those with low EV miR-21-5p levels. During the 30-month follow-up phase, $42 \%$ of the patients with elevated serum EV miR-21-5p levels died, compared with $10 \%$ of the individuals with lower levels. Therefore, serum EV miR-21-5p levels adjusted for EV capacity strongly predicted disease progression and mortality (117).

Another study analyzed the expression levels of 5 exosomal miRNAs in serum from patients with IPF and found that miR-16, miR-21, miR-26a, miR-210 and let-7d were downregulated in serum exosomes from patients with IPF, although only miR-16 and let-7d had a statistically significant difference, compared with healthy subjects. Moreover, let-7d was shown to be anti-fibrotic (118).

A previous study demonstrated that the expression of miR-22 in the sera of bleomycin-induced PF in mice was increased by up to 2-fold compared with the control group (119). In vitro experiments demonstrated that exosomal miR-22 inhibited TGF- $\beta 1$-induced $\alpha$-SMA expression through the ERK1/2 signaling pathway, indicating that this miRNA could regulate fibroblast-to-myofibroblast differentiation to ameliorate PF (119). It was also previously demonstrated that serum exosome miR-18 expression was upregulated 8 -fold in bleomycin-induced PF mice, compared with the wild-type group. In vivo, a miR-16 mimic downregulated the expression of the rapamycin-insensitive companion of mTOR complex 2 and the TGF $\beta$-1-induced expression of secreted 
protein acidic and rich in cysteine (SPARC) in human lung fibroblasts to reduce PF in lung tissue. This demonstrated that exosome-derived miR-16 may play a role in PF through the mTOR-SPARC signaling pathway (120). Blood testing is minimally invasive, and exosomal miRNAs are stable. Therefore, blood exosomal miRNAs may serve as reliable markers for the diagnosis and prognosis of IPF, as well as for the assessment of disease severity. Exosomes may serve as miRNA delivery platforms for the targeted treatment of IPF.

Macrophage-derived exosomal miRNAs. Although macrophages are critical cells in the immune response, they can also promote PF (96). Macrophages differentiate into two distinct subsets: i) Classically activated or M1 macrophages, characterized by the secretion of pro-inflammatory cytokines and chemokines (such as IL-1 $\beta$, IL-6, IL-12, IL-23, TNF- $\alpha$ and CCL2); or ii) alternatively activated or M2 macrophages that produce anti-inflammatory cytokines and chemokines (IL-4, IL-13, TGF- $\beta$ and CXCL-8) (121). miRNAs may also mediate macrophage polarization. A previous study examining the regulation of M2 macrophage polarization in radiation-induced PF demonstrated that miR-21 and miR-155 played a fibrogenic role, whereas let-7i and miR-107, -126, -140, and -511 were anti-fibrotic (122). In another study, in a rat model of PF, miR-328 expression was significantly upregulated, and family with sequence similarity 13 member A (FAM13A) expression was notably downregulated. In addition, both miR-328 overexpression and FAM13A silencing promoted the proliferation of lung fibroblasts and deposition of ECM. By contrast, the overexpression of M2 macrophage-derived exosomal miR-328 contributed to enhanced fibroblast proliferation and promoted PF through the regulation of FAM13A in vivo and in vitro (123). Exosomal miRNA profiles derived from macrophages exposed to silica have been examined using high-throughput sequencing (124). A total of 298 miRNA molecules were differentially expressed (155 upregulated and 143 downregulated), compared with unexposed macrophages; additional research found that plasma exosomal miR-125a-5p expression was upregulated in patients with silicosis (124). In vitro experiments revealed that miR-125a-5p may target the ID1 and TGF- $\beta /$ SMAD1 signaling pathway, promoting fibroblast differentiation to myofibroblasts and the development of PF (124). In a recent study, the analysis of exosomal miRNAs demonstrated that miR-142-3p was significantly elevated in the sputum (8.06-fold) and plasma (1.64-fold) of patients with IPF. Correlation analysis revealed that exosomal miR-142-3p correlate positively with the percentage of macrophages in the sputum of patients with IPF. In addition, macrophage-derived exosomes inhibit TGF- $\beta$ receptor 1 by delivering anti-fibrotic miR-142-3p to AECs and lung fibroblasts, thereby alleviating PF (125). Therefore, there is evidence that the effect of exosomal miRNAs derived from macrophages contributes to the proliferation of fibroblasts and the progression of PF.

Exosomal miRNAs derived from other cells. Mesenchymal stem cells (MSCs) have been shown to be effective in the treatment of IPF (126). Multiple phase-I clinical trials have been conducted to ensure the safety of MSC treatment (127). In one particular trial, the 2-year survival rate of 14 patients with IPF following the first administration of adipose-derived stem cells (ADSCs) was $100 \%$, the median overall progression-free survival time was 26 months, and overall survival was 32 months (128). In general, MSCs have the therapeutic ability to repair damaged tissue by releasing EVs that carry various dynamic cargos. In particular, exosomes extracted from bone marrow-derived MSCs (BMSCs), contain various proteins, mRNA transcripts and miRNAs that affect various biological activities during tissue healing (129). A previous study demonstrated that the overexpression of miR-29b-3p from BMSC EVs suppressed the proliferation, migration, invasion and differentiation of lung interstitial fibroblasts and relieved IPF through Frizzled 6 (130).

Moreover, it has been reported that MSC-derived EVs can attenuate radiation-induced lung fibrosis by reducing DNA damage by downregulating the ataxia telangiectasia mutated (ATM)/P53/P21 signaling pathway; in addition, the downregulation of ATM has been shown to be regulated by miR-214-3p, which is enriched in MSC-derived EVs (131). Another study found that BMSC-EVs inhibit lung fibroblast activation and postpone the advancement of the IPF in a murine model. miR-186 is downregulated in IPF but enriched in BMSC-derived EVs, suggesting that miR-186 transported by BMSC EVs could promote fibroblast activation and alleviate PF through downregulation of miR-186 target gene with SRY-related HMG box transcription factor 4 and its downstream gene, Dickkopf-1 (132).

Other biological sources of therapeutic EVs include differentiated cells, such as lung epithelial cells, lung fibroblasts and cells of the immune system (133). EV-associated miRNAs, such as miR-142-3p, miR-144-3p, miR-34b and miR-503-5p, which target diverse profibrotic pathways, have been found to ameliorate bleomycin-induced PF by lung-derived epithelial cell EVs collected from syndecan-1 deficient mice (134). miR-223 and miR-27b-3p in exosomes derived from vascular endothelial cells and AEC-IIs have been shown to inhibit regulator of $\mathrm{G}$ protein signaling-1 (RGS1) expression and regulate the frequency of Flt $3^{+}$, Tie $2^{+}$alveolar macrophages through calcium-dependent signaling, thereby ameliorating bleomycin-induced acute lung injury and PF (135). Furthermore, the inhalation of lung spheroid cell (LSC)-secretome (LSC-Sec) and exosomes (LSC-Exo) has been examined in various murine models of lung damage and fibrosis. In LSC-Exo and MSC-Exo specimens, $\sim 600$ distinct miRNA molecules were identified. hsa-miR-99a-5p, hsa-miR-100-5p and miR-30a-3p were among the most upregulated miRNAs in LSC-Exo, whereas hsa-let-7a-5p and hsa-let-7f-5p were the most upregulated in the MSC-Exo samples. By re-establishing normal alveolar structure and decreasing collagen deposition and myofibroblast proliferation, LSC-Sec and LSC-Exo therapies may ameliorate and repair bleomycinand silica-induced PF (136). It has also been demonstrated that human bronchial epithelial cell (HBEC)-derived EVs prevent TGF- $\beta$-mediated activation of both myofibroblast differentiation and lung epithelial cellular senescence by inhibiting WNT signaling. miR-16, miR-26a, miR-26b, miR-141, miR-148a and miR-200a are mechanistically involved in suppressing WNT5A and WNT10B expression in lung fibroblasts in vitro and in reducing WNT3A, WNT5A and WNT10B expression in HBECs, among 
the enriched miRNAs derived from HBEC EVs. Further research has revealed that HBEC EVs treatment may be a viable anti-fibrotic therapy for IPF due to miRNA-mediated reduction of TGF- $\beta$-WNT crosstalk (137).

\section{Conclusions and future prospects}

As discussed in the present review article, previous studies have clarified the role of miRNAs and exosomes in the pathogenesis of IPF, and have suggested that circulating miRNAs and exosomes may become biomarkers for the diagnosis and prognosis of IPF and potential therapeutic targets for its treatment. However, several important issues need to be clarified to determine the applicability of miRNAs and exosomes in IPF diagnosis and treatment.

Firstly, different laboratories use different techniques for the detection, isolation and analysis of exosomes, which can confound the interpretation of results. Exosomes are nanoscopic particles that are still difficult to detect and isolate even using advanced technologies. With exosome isolation and identification techniques continuously evolving, there is a lack of standardization; hence, the employment of reproducible and standardized methodology to quantify specific exosomes in clinical samples is still a challenge.

In addition, exosomes originate from various body fluids, such as saliva, sputum, exhaled breath condensates, BALF, blood, urine, ascites and cerebrospinal fluid (138), and their cargos are organ-, tissue- and cell-specific. Thus, due to the heterogeneity of exosomes, their cargos and functions, precise and accurate characterization methods are necessary. Investigators need to further explore novel techniques to identify them, such as miRNAs combined with traditional biomarkers, such as KL6, metalloprotease and surfactant proteins $\mathrm{A}$ and $\mathrm{D}$, to obtain insight into the pathophysiology of IPF. On the other hand, the EV isolate technique, and research design are highly heterogeneous (139).

Moreover, specific methods for the delivery of potentially therapeutic miRNAs in exosomes to individual cells or organs have not yet been established; therefore, further investigations into the use of exosomes as miRNA delivery platforms that can accurately deliver miRNAs to injured lung epithelial cells are required; these may provide novel therapeutic strategies for the treatment of IPF.

Furthermore, miRNAs are found in large amounts in the body, and different miRNA molecules can regulate one target gene, and conversely, one miRNA can regulate multiple target genes. This complex association has kept much of the current research in the exploratory stage. Similarly, in the pathogenesis of PF, one miRNA can regulate multiple pathological aspects of PF (such as miR-21), and one pathological pathway may be subjected to regulation by multiple miRNA molecules, which represents a complex regulatory network that needs further study.

The epigenetic profile of miRNAs renders them one of the molecular classes that warrant consideration in future studies. Moreover, whether they can participate in the signaling pathways and autonomous biochemical reactions under appropriate circumstances remains to be clarified (44).

Lastly, large-scale randomized controlled trials are required to determine the efficacy of particular treatment strategies and effective preventive measures to reduce the mortality of patients with IPF.

In conclusion, exosomal miRNAs can mediate cell-to-cell communications, which has become a topic of extensive research. Previous studies have indicated that the abnormal expression of exosomal miRNAs in lung diseases (such as COPD, asthma, lung cancer and IPF) is essential to their pathogenesis. The potential for miRNA molecules to be used as biomarkers for the diagnosis and management of PF, and as therapeutic tools in clinical practice remains to be investigated. The study of exosomal miRNAs in IPF is still in its infancy, and further research is required to investigate the role of exosomal miRNAs in PF pathogenesis and progression. Future studies on the contribution of exosomal miRNA to the pathogenesis of PF may clarify the prospects for their future clinical application in this field.

\section{Acknowledgements}

Not applicable.

\section{Funding}

The present study was supported by the Project of The Social Development of Zhenjiang City of China (grant no. SH2020047).

\section{Availability of data and materials}

Data sharing does not apply to this article, as no datasets were generated or analyzed during the current study.

\section{Authors' contributions}

TY performed the literature search and wrote the manuscript. $\mathrm{JZ}$ and YL contributed to the literature search and in the revision of the manuscript. JW supervised the preparation of the manuscript and was also involved in the revision of the manuscript. All authors have read and approved the final manuscript. Data authentication is not applicable.

\section{Ethics approval and consent to participate}

Not applicable.

\section{Patient consent for publication}

Not applicable.

\section{Competing interests}

The authors declare that they have no competing interests.

\section{References}

1. Raghu G, Remy-Jardin M, Myers JL, Richeldi L, Ryerson CJ, Lederer DJ, Behr J, Cottin V, Danoff SK, Morell F, et al: Diagnosis of idiopathic pulmonary fibrosis. An official ATS/ERS/JRS/ALAT clinical practice guideline. Am J Respir Crit Care Med 198: e44-e68, 2018

2. Lederer DJ and Martinez FJ: Idiopathic pulmonary fibrosis. N Engl J Med 378: 1811-1823, 2018. 
3. Schamberger AC, Schiller HB, Fernandez IE, Sterclova M, Heinzelmann K, Hennen E, Hatz R, Behr J, Vašáková M, Mann M, et al: Glutathione peroxidase 3 localizes to the epithelial lining fluid and the extracellular matrix in interstitial lung disease. Sci Rep 6: 29952, 2016.

4. Zhang L, Wang Y, Pandupuspitasari NS, Wu G, Xiang X, Gong Q, Xiong W, Wang CY, Yang P and Ren B: Endoplasmic reticulum stress, a new wrestler, in the pathogenesis of idiopathic pulmonary fibrosis. Am J Transl Res 9: 722-735, 2017.

5. Kirby T: Living with idiopathic pulmonary fibrosis. Lancet Respir Med 9: 136-138, 2021.

6. Shenderov K, Collins SL, Powell JD and Horton MR: Immune dysregulation as a driver of idiopathic pulmonary fibrosis. J Clin Invest 131: e143226, 2021.

7. Guenther A, Krauss E, Tello S, Wagner J, Paul B, Kuhn S, Maurer O, Heinemann S, Costabel U, Barbero MAN, et al: The European IPF registry (eurIPFreg): Baseline characteristics and survival of patients with idiopathic pulmonary fibrosis. Respir Res 19: 141, 2018

8. Gao J, Kalafatis D, Carlson L, Pesonen IHA, Li CX, Wheelock Å, Magnusson JM and Sköld CM: Baseline characteristics and survival of patients of idiopathic pulmonary fibrosis: A longitudinal analysis of the Swedish IPF Registry. Respir Res 22: 40 , 2021

9. Maher TM, Costabel U, Glassberg MK, Kondoh Y, Ogura T, Scholand MB, Kardatzke D, Howard M, Olsson J, Neighbors M, et al: Phase 2 trial to assess lebrikizumab in patients with idiopathic pulmonary fibrosis. Eur Respir J 57: 1902442, 2021.

10. Di Martino E, Provenzani A, Vitulo P and Polidori P: Systematic review and meta-analysis of pirfenidone, nintedanib, and pamrevlumab for the treatment of idiopathic pulmonary fibrosis. Ann Pharmacother 55: 723-731, 2021.

11. Raghu G, van den Blink B, Hamblin MJ, Brown AW, Golden JA, Ho LA, Wijsenbeek MS, Vasakova M, Pesci A, Antin-Ozerkis DE, et al: Effect of recombinant human pentraxin 2 vs placebo on change in forced vital capacity in patients with idiopathic pulmonary fibrosis: A randomized clinical trial. JAMA 319: 2299-2307, 2018

12. Maher TM, van der Aar EM, Van de Steen O, Allamassey L, Desrivot J, Dupont S, Fagard L, Ford P, Fieuw A and Wuyts W: Safety, tolerability, pharmacokinetics, and pharmacodynamics of GLPG1690, a novel autotaxin inhibitor, to treat idiopathic pulmonary fibrosis (FLORA): A phase 2 a randomised placebo-controlled trial. Lancet Respir Med 6: 627-635, 2018.

13. Abuserewa ST, Duff R and Becker G: Treatment of idiopathic pulmonary fibrosis. Cureus 13: e15360, 2021

14. Brigstock DR: Extracellular vesicles in organ fibrosis: Mechanisms, therapies, and diagnostics. Cells 10: 1596, 2021.

15. Yamada M: Extracellular vesicles: Their emerging roles in the pathogenesis of respiratory diseases. Respir Investig 59: 302-311, 2021.

16. Anderson HC: Vesicles associated with calcification in the matrix of epiphyseal cartilage. J Cell Biol 41: 59-72, 1969.

17. György B, Szabó TG, Pásztói M, Pál Z, Misják P, Aradi B, László V, Pállinger E, Pap E, Kittel A, et al: Membrane vesicles, current state-of-the-art: Emerging role of extracellular vesicles. Cell Mol Life Sci 68: 2667-2688, 2011.

18. Pan BT, Teng K, Wu C, Adam M and Johnstone RM: Electron microscopic evidence for externalization of the transferrin receptor in vesicular form in sheep reticulocytes. J Cell Biol 101: 942-948, 1985

19. Menck K, Sivaloganathan S, Bleckmann A and Binder C: Microvesicles in cancer: Small size, large potential. Int J Mol Sci 21: 5373, 2020.

20. Pegtel DM and Gould SJ: Exosomes. Annu Rev Biochem 88 : 487-514, 2019

21. Cocozza F, Grisard E, Martin-Jaular L, Mathieu M and Théry C: SnapShot: Extracellular vesicles. Cell 182: 262-262.e1, 2020.

22. Zhang H, Freitas D, Kim HS, Fabijanic K, Li Z, Chen H, Mark MT, Molina H, Martin AB, Bojmar L, et al: Identification of distinct nanoparticles and subsets of extracellular vesicles by asymmetric flow field-flow fractionation. Nat Cell Biol 20: 332-343, 2018

23. Anand S, Samuel M and Mathivanan S: Exomeres: A new member of extracellular vesicles family. Subcell Biochem 97: 89-97, 2021.

24. Kučuk N, Primožič M, Knez Ž and Leitgeb M: Exosomes engineering and their roles as therapy delivery tools, therapeutic targets, and biomarkers. Int J Mol Sci 22: 9543, 2021.
25. Kodam SP and Ullah M: Diagnostic and therapeutic potential of extracellular vesicles. Technol Cancer Res Treat 20 $15330338211041203,2021$.

26. Shao H, Im H, Castro CM, Breakefield X, Weissleder R and Lee H: New technologies for analysis of extracellular vesicles. Chem Rev 118: 1917-1950, 2018.

27. Yang D, Zhang W, Zhang H, Zhang F, Chen L, Ma L, Larcher LM, Chen S, Liu N, Zhao Q, et al: Progress, opportunity, and perspective on exosome isolation-efforts for efficient exosome-based theranostics. Theranostics 10: 3684-3707, 2020.

28. Théry C, Zitvogel L and Amigorena S: Exosomes: Composition, biogenesis and function. Nat Rev Immunol 2: 569-579, 2002.

29. Trajkovic K, Hsu C, Chiantia S, Rajendran L, Wenzel D, Wieland F, Schwille P, Brügger B and Simons M: Ceramide triggers budding of exosome vesicles into multivesicular endosomes. Science 319: 1244-1247, 2008.

30. van Niel G, Porto-Carreiro I, Simoes S and Raposo G: Exosomes: A common pathway for a specialized function. J Biochem 140: 13-21, 2006.

31. Vietri M, Radulovic $M$ and Stenmark $H$ : The many functions of ESCRTs. Nat Rev Mol Cell Biol 21: 25-42, 2020.

32. Ju Y, Bai H, Ren L and Zhang L: The role of exosome and the ESCRT pathway on enveloped virus infection. Int J Mol Sci 22: 9060, 2021.

33. Sun R, Liu Y, Lu M, Ding Q, Wang P, Zhang H, Tian X, Lu P, Meng D, Sun N, et al: ALIX increases protein content and protective function of iPSC-derived exosomes. J Mol Med (Berl) 97: 829-844, 2019.

34. Han Q, Lv L, Wei J, Lei X, Lin H, Li G, Cao J, Xie J, Yang W, Wu S, et al: Vps4A mediates the localization and exosome release of $\beta$-catenin to inhibit epithelial-mesenchymal transition in hepatocellular carcinoma. Cancer Lett 457: 47-59, 2019.

35. Kunadt M, Eckermann K, Stuendl A, Gong J, Russo B, Strauss K, Rai S, Kügler S, Falomir Lockhart L, Schwalbe M, et al: Extracellular vesicle sorting of $\alpha$-Synuclein is regulated by sumoylation. Acta Neuropathol 129: 695-713, 2015

36. Chang HM and Yeh ETH: SUMO: From bench to bedside. Physiol Rev 100: 1599-1619, 2020.

37. de Gassart A, Géminard C, Février B, Raposo G and Vidal M: Lipid raft-associated protein sorting in exosomes. Blood 102 4336-4344, 2003

38. Rana S and Zöller M: Exosome target cell selection and the importance of exosomal tetraspanins: A hypothesis. Biochem Soc Trans 39: 559-562, 2011.

39. van Niel G, Charrin S, Simoes S, Romao M, Rochin L, Saftig P, Marks MS, Rubinstein E and Raposo G: The tetraspanin CD63 regulates ESCRT-Independent and -Dependent endosomal sorting during melanogenesis. Dev Cell 21: 708-721, 2011.

40. Chairoungdua A, Smith DL, Pochard P, Hull M and Caplan MJ: Exosome release of $\beta$-catenin: A novel mechanism that antagonizes Wnt signaling. J Cell Biol 190: 1079-1091, 2010.

41. Doyle LM and Wang MZ: Overview of extracellular vesicles, their origin, composition, purpose, and methods for exosome isolation and analysis. Cells 8: 727, 2019.

42. Dang VD, Jella KK, Ragheb RRT, Denslow ND and Alli AA Lipidomic and proteomic analysis. of exosomes from mouse cortical collecting duct cells. FASEB J 31: 5399-5408, 2017.

43. O'Brien K, Breyne $\mathrm{K}$, Ughetto $\mathrm{S}$, Laurent LC and Breakefield XO: RNA delivery by extracellular vesicles in mammalian cells and its applications. Nat Rev Mol Cell Biol 21: 585-606, 2020.

44. Kalluri R and LeBleu VS: The biology, function, and biomedical applications of exosomes. Science 367: eaau6977, 2020.

45. Saad MH, Badierah R, Redwan EM and El-Fakharany EM: A comprehensive insight into the role of exosomes in viral infection: Dual faces bearing different functions. Pharmaceutics 13 1405,2021

46. Gurunathan S, Kang MH, Qasim M, Khan K and Kim JH: Biogenesis, membrane trafficking, functions, and next generation nanotherapeutics medicine of extracellular vesicles. Int J Nanomedicine 16: 3357-3383, 2021.

47. Zhang Q, Higginbotham JN, Jeppesen DK, Yang YP, Li W, McKinley ET, Graves-Deal R, Ping J, Britain CM, Dorsett KA, et al: Transfer of functional cargo in exomeres. Cell Rep 27: 940-954.e6, 2019.

48. Krol J, Loedige I and Filipowicz W: The widespread regulation of microRNA biogenesis, function and decay. Nat Rev Genet 11: 597-610, 2010.

49. Mohr AM and Mott JL: Overview of MicroRNA biology. Semin Liver Dis 35: 3-11, 2015 . 
50. Valadi H, Ekström K, Bossios A, Sjöstrand M, Lee JJ and Lötvall JO: Exosome-mediated transfer of mRNAs and microRNAs is a novel mechanism of genetic exchange between cells. Nat Cell Biol 9: 654-659, 2007.

51. Shao N, Xue L, Wang R, Luo K, Zhi F and Lan Q: MiR-454-3p is an exosomal biomarker and functions as a tumor suppressor in glioma. Mol Cancer Ther 18: 459-469, 2019.

52. Qiu Y, Li P, Zhang Z and Wu M: Insights into exosomal Non-coding RNAs sorting mechanism and clinical application. Front Oncol 11: 664904, 2021.

53. Schirle NT, Sheu-Gruttadauria J and MacRae IJ: Structural basis for microRNA targeting. Science 346: 608-613, 2014

54. Methods in MicroRNA biogenesis, identification, function and decay. Methods 152: 1-2, 2019

55. Zhang J, Li S, Li L, Li M, Guo C, Yao J and Mi S: Exosome and exosomal microRNA: Trafficking, sorting, and function. Genomics Proteomics Bioinformatics 13: 17-24, 2015

56. Guduric-Fuchs J, O'Connor A, Camp B, O'Neill CL, Medina RJ and Simpson DA: Selective extracellular vesicle-mediated export of an overlapping set of microRNAs from multiple cell types. BMC Genomics 13: 357, 2012.

57. Donzelli J, Proestler E, Riedel A, Nevermann S, Hertel B, Guenther A, Gattenlöhner S, Savai R, Larsson K and Saul MJ: Small extracellular vesicle-derived miR-574-5p regulates PGE2-biosynthesis via TLR7/8 in lung cancer. J Extracell Vesicles 10: e12143, 2021

58. Melo SA, Sugimoto H, O'Connell JT, Kato N, Villanueva A, Vidal A, Qiu L, Vitkin E, Perelman LT, Melo CA, et al: Cancer exosomes perform Cell-Independent MicroRNA biogenesis and promote tumorigenesis. Cancer Cell 26: 707-721, 2014.

59. Villarroya-Beltri C, Gutiérrez-Vázquez C, Sánchez-Cabo F, Pérez-Hernández D, Vázquez J, Martin-Cofreces N, Martinez-Herrera DJ, Pascual-Montano A, Mittelbrunn M and Sánchez-Madrid F: Sumoylated hnRNPA2B1 controls the sorting of miRNAs into exosomes through binding to specific motifs. Nat Commun 4: 2980, 2013.

60. Santangelo L, Giurato G, Cicchini C, Montaldo C, Mancone C, Tarallo R, Battistelli C, Alonzi T, Weisz A and Tripodi M: The RNA-Binding Protein SYNCRIP Is a component of the hepatocyte exosomal machinery controlling MicroRNA sorting. Cell Rep 17: 799-808, 2016.

61. Boateng E and Krauss-Etschmann S: miRNAs in lung development and diseases. Int J Mol Sci 21: 2765, 2020.

62. Bersimbaev R, Aripova A, Bulgakova O, Kussainova A Akparova A and Izzotti A: The plasma levels of hsa-miR-19b-3p, hsa-miR-125b-5p, and hsamiR-320c in patients with asthma, COPD and asthma-COPD overlap syndrome (ACOS). MicroRNA 10: 130-138, 2021

63. Zeng Q and Zeng J: Inhibition of miR-494-3p alleviates oxidative stress-induced cell senescence and inflammation in the primary epithelial cells of COPD patients. Int Immunopharmacol 92: 107044, 2021.

64. Weidner J, Bartel S, Kılıç A, Zissler UM, Renz H, Schwarze J, Schmidt-Weber CB, Maes T, Rebane A, Krauss-Etschmann S and Rådinger M: Spotlight on microRNAs in allergy and asthma. Allergy 76: 1661-1678, 2021.

65. Wardzyńska A, Pawełczyk M, Rywaniak J, Makowska J, Jamroz-Brzeska J and Kowalski ML: Circulating miRNA expression in asthmatics is age-related and associated with clinical asthma parameters, respiratory function and systemic inflammation. Respir Res 22: 177, 2021.

66. Zhong S, Golpon H, Zardo P and Borlak J: MiRNAs in lung cancer. A systematic review identifies predictive and prognostic miRNA candidates for precision medicine in lung cancer. Transl Res 230: 164-196, 2021

67. Cainap C, Balacescu O, Cainap SS and Pop LA: Next generation sequencing technology in lung cancer diagnosis. Biology (Basel) 10: 864, 2021

68. Yang G, Yang L, Wang W, Wang J, Wang J and Xu Z: Discovery and validation of extracellular/circulating microRNAs during idiopathic pulmonary fibrosis disease progression. Gene 562: 138-144, 2015.

69. Zhang H, Song M, Guo J, Ma J, Qiu M and Yang Z: The function of non-coding RNAs in idiopathic pulmonary fibrosis. Open Med (Wars) 16: 481-490, 2021.

70. Wang Q, Xie ZL, Wu Q, Jin ZX, Yang C and Feng J: Role of various imbalances centered on alveolar epithelial cell/fibroblast apoptosis imbalance in the pathogenesis of idiopathic pulmonary fibrosis. Chin Med J (Engl) 134: 261-274, 2021.
71. Mao C, Zhang J, Lin S, Jing L, Xiang J, Wang M, Wang B, Xu P, Liu W, Song X and Lv C: Mi RNA -30a inhibits AEC s-II apoptosis by blocking mitochondrial fission dependent on Drp-1. J Cell Mol Med 18: 2404-2416, 2014.

72. Matsushima S and Ishiyama J: MicroRNA-29c regulates apoptosis sensitivity via modulation of the cell-surface death receptor, Fas, in lung fibroblasts. Am J Physiol Lung Cell Mol Physiol 311: L1050-L1061, 2016.

73. Shetty SK, Tiwari N, Marudamuthu AS, Puthusseri B, Bhandary YP, Fu J, Levin J, Idell S and Shetty S: p53 and miR-34a feedback promotes lung epithelial injury and pulmonary fibrosis. Am J Pathol 187: 1016-1034, 2017.

74. Milanovic M, Fan DNY, Belenki D, Däbritz JHM, Zhao Z, Yu Y, Dörr JR, Dimitrova L, Lenze D, Monteiro Barbosa IA, et al: Senescence-associated reprogramming promotes cancer stemness. Nature 553: 96-100, 2018

75. Wolters PJ, Collard HR and Jones KD: Pathogenesis of idiopathic pulmonary fibrosis. Annu Rev Pathol 9: 157-179, 2014.

76. Hussen BM, Shoorei H, Mohaqiq M, Dinger ME, Hidayat HJ, Taheri $\mathrm{M}$ and Ghafouri-Fard S: The impact of Non-coding RNAs in the epithelial to mesenchymal transition. Front Mol Biosci 8: 665199, 2021.

77. Sun J,Li Q, Lian X, Zhu Z, Chen X, Pei W, Li S, Abbas A, Wang Y and Tian L: MicroRNA-29b mediates lung mesenchymal-epithelial transition and prevents lung fibrosis in the silicosis model. Mol Ther Nucleic Acids 14: 20-31, 2019.

78. Qi Y, Zhao A, Yang P, Jin L and Hao C: MiR-34a-5p Attenuates EMT through targeting SMAD4 in silica-induced pulmonary fibrosis. J Cell Mol Med 24: 12219-12224, 2020.

79. Jeong MH, Kim HR, Park YJ, Chung KH and Kim HS: Reprogrammed lung epithelial cells by decrease of miR-451a in extracellular vesicles contribute to aggravation of pulmonary fibrosis. Cell Biol Toxicol: Aug 30, 2021 (Epub ahead of print).

80. Liu Y, Nie H, Ding Y, Hou Y, Mao K and Cui Y: MiRNA, a new treatment strategy for pulmonary fibrosis. Curr Drug Targets 22: 793-802, 2021

81. Rajasekaran S, Rajaguru P and Sudhakar Gandhi PS: MicroRNAs as potential targets for progressive pulmonary fibrosis. Front Pharmacol 6: 254,2015.

82. Wei P, Xie Y, Abel PW, Huang Y, Ma Q, Li L, Hao J, Wolff DW, Wei T and Tu Y: Transforming growth factor (TGF)- 31 -induced miR-133a inhibits myofibroblast differentiation and pulmonary fibrosis. Cell Death Dis 10: 670, 2019.

83. Xiao T, Zou Z, Xue J, Syed BM, Sun J, Dai X, Shi M, Li J, Wei S, Tang H, et al: LncRNA H19-mediated M2 polarization of macrophages promotes myofibroblast differentiation in pulmonary fibrosis induced by arsenic exposure. Environ Pollut 268(Pt A): 115810, 2021.

84. Wang P, Xiao T, Li J, Wang D, Sun J, Cheng C, Ma H, Xue J, Li Y, Zhang A and Liu Q: MiR-21 in EVs from pulmonary epithelial cells promotes myofibroblast differentiation via glycolysis in arsenic-induced pulmonary fibrosis. Environ Pollut 286: 117259, 2021.

85. Huang Y, Xie Y, Abel PW, Wei P, Plowman J, Toews ML, Strah H, Siddique A, Bailey KL and Tu Y: TGF- $\beta 1$-induced miR-424 promotes pulmonary myofibroblast differentiation by targeting Slit2 protein expression. Biochem Pharmacol 180: 114172,2020

86. Chen X, Shi C, Wang C, Liu W, Chu Y, Xiang Z, Hu K, Dong P and Han X: The role of miR-497-5p in myofibroblast differentiation of LR-MSCs and pulmonary fibrogenesis. Sci Rep 7: 40958, 2017.

87. Wang $\mathrm{C}, \mathrm{Gu} \mathrm{S}$, Cao H, Li Z, Xiang Z, Hu K and Han X: MiR-877-3p targets Smad7 and is associated with myofibroblast differentiation and bleomycin-induced lung fibrosis. Sci Rep 6: $30122,2016$.

88. Akbari Dilmaghnai N, Shoorei H, Sharifi G, Mohaqiq M, Majidpoor J, Dinger ME, Taheri M and Ghafouri-Fard S: Non-coding RNAs modulate function of extracellular matrix proteins. Biomed Pharmacother 136: 111240, 2021.

89. Li J, Zhang X, Wang T, Li J, Su Q, Zhong C, Chen Z and Liang Y: The MIR 155 host gene/microRNA-627/HMGB1/NF- $\mathrm{B}$ loop modulates fibroblast proliferation and extracellular matrix deposition. Life Sci 269: 119085, 2021.

90. Wang YC, Xie H, Zhang YC, Meng QH, Xiong MM, Jia MW, Peng F and Tang DL: Exosomal miR-107 antagonizes profibrotic phenotypes of pericytes by targeting a pathway involving HIF-1 $\alpha /$ Notch1/PDGFR $\beta / Y A P 1 / T w i s t 1$ axis in vitro. Am J Physiol-Heart Circ Physiol 320: H520-H534, 2021 
91. Phan THG, Paliogiannis P, Nasrallah GK, Giordo R, Eid AH, Fois AG, Zinellu A, Mangoni AA and Pintus G: Emerging cellular and molecular determinants of idiopathic pulmonary fibrosis. Cell Mol Life Sci 78: 2031-2057, 2021.

92.Zhang S, Jia X, Zhang Q, Zhang L, Yang J, Hu C, Shi J, Jiang X, $\mathrm{Lu} J$ and Shen H: Neutrophil extracellular traps activate lung fibroblast to induce polymyositis-related interstitial lung diseases via TLR9-miR-7-Smad2 pathway. J Cell Mol Med 24: $1658-1669,2020$

93. Chen YC, Chen BC, Yu CC, Lin SH and Lin CH: MiR-19a, -19b, and -26b Mediate CTGF expression and pulmonary fibroblast differentiation. J Cell Physiol 231: 2236-2248, 2016.

94. Yi M, Liu B, Tang Y, Li F, Qin W and Yuan X: Irradiated human umbilical vein endothelial cells undergo endothelial-mesenchymal transition via the Snail/miR-199a-5p axis to promote the differentiation of fibroblasts into myofibroblasts. Biomed Res Int 2018: 4135806, 2018.

95. Desai O, Winkler J, Minasyan M and Herzog EL: The role of immune and inflammatory cells in idiopathic pulmonary fibrosis. Front Med (Lausanne) 5: 43, 2018.

96. Heukels P, Moor CC, von der Thüsen JH, Wijsenbeek MS and Kool M: Inflammation and immunity in IPF pathogenesis and treatment. Respir Med 147: 79-91, 2019.

97. Zhu M, An Y, Zhang X, Wang Z and Duan H: Experimental pulmonary fibrosis was suppressed by microRNA-506 through NF-kappa-mediated apoptosis and inflammation. Cell Tissue Res 378: 255-265, 2019.

98. Zhou L, Li P, Zhang M, Han B, Chu C, Su X, Li B, Kang H, Ning J, Zhang B, et al: Carbon black nanoparticles induce pulmonary fibrosis through NLRP3 inflammasome pathway modulated by miR-96 targeted FOXO3a. Chemosphere 241 125075,2020

99. Mo Y, Zhang Y, Wan R, Jiang M, Xu Y and Zhang Q: MiR-21 mediates nickel nanoparticle-induced pulmonary injury and fibrosis. Nanotoxicology 14: 1175-1197, 2020.

100. Tan S and Chen S: The mechanism and effect of autophagy, apoptosis, and pyroptosis on the progression of silicosis. Int J Mol Sci 22: 8110, 2021

101. Zhao H, Wang Y, Qiu T, Liu W and Yao P: Autophagy, an important therapeutic target for pulmonary fibrosis diseases. Clin Chim Acta 502: 139-147, 2020.

102. Lv X, Li K and Hu Z: Autophagy and pulmonary fibrosis. Adv Exp Med Biol 1207: 569-579, 2020

103. Xu T, Yan W, Wu Q, Xu Q, Yuan J, Li Y, Li P, Pan H and Ni C: MiR-326 inhibits inflammation and promotes autophagy in Silica-Induced pulmonary fibrosis through targeting TNFSF14 and PTBP1. Chem Res Toxicol 32: 2192-2203, 2019.

104. Han R, Ji X, Rong R, Li Y, Yao W, Yuan J, Wu Q, Yang J, Yan W, Han L, et al: MiR-449a regulates autophagy to inhibit silica-induced. pulmonary fibrosis through targeting Bcl2. J Mol Med (Berl) 94: 1267-1279, 2016.

105. ZarebaL,Szymanski J,HomoncikZand Czystowska-KuzmiczM: EVs from BALF-Mediators of inflammation and potential biomarkers in lung diseases. Int J Mol Sci 22: 3651, 2021.

106. Shaba E, Landi C, Carleo A, Vantaggiato L, Paccagnini E, Gentile M, Bianchi L, Lupetti P, Bargagli E, Prasse A and Bini L: Proteome characterization of BALF extracellular vesicles in idiopathic pulmonary fibrosis: Unveiling undercover molecular pathways. Int J Mol Sci 22: 5696, 2021

107. Rodríguez M, Silva J, López-Alfonso A, López-Muñiz MB, Peña C, Domínguez G, García JM, López-Gónzalez A, Méndez M, Provencio M, et al: Different exosome cargo from plasma/bronchoalveolar lavage in non-small-cell lung cancer. Genes Chromosomes Cancer 53: 713-724, 2014.

108. Liu B, Jiang T, Hu X, Liu Z, Zhao L, Liu H, Liu Z and Ma L: Downregulation of microRNA-30a in bronchoalveolar lavage fluid from idiopathic pulmonary fibrosis patients. Mol Med Rep 18: 5799-5806, 2018.

109. Zhu L, Chen Y, Chen M and Wang W: Mechanism of miR-204-5p in exosomes derived from bronchoalveolar lavage fluid on the progression of pulmonary fibrosis via AP1S2. Ann Transl Med 9: 1068, 2021.

110. Guiot J, Demarche S, Henket M, Paulus V, Graff S, Schleich F, Corhay JL, Louis R and Moermans C: Methodology for Sputum Induction and Laboratory Processing. J Vis Exp (130): 56612, 2017.

111. Pastor L, Vera E, Marin JM and Sanz-Rubio D: Extracellular Vesicles from Airway Secretions: New insights in lung diseases. Int J Mol Sci 22: 583, 2021.
112. Guiot J, Henket M, Corhay JL, Moermans C and Louis R: Sputum biomarkers in IPF: Evidence for raised gene expression and protein level of IGFBP-2, IL-8 and MMP-7. PLoS One 12: e0171344, 2017.

113. Njock MS, Guiot J, Henket MA, Nivelles O, Thiry M, Dequiedt F, Corhay JL, Louis RE and Struman I: Sputum exosomes: Promising biomarkers for idiopathic pulmonary fibrosis. Thorax 74: 309-312, 2019.

114. Trappe A, Donnelly SC, McNally P and Coppinger JA: Role of extracellular vesicles in chronic lung disease. Thorax 76 1047-1056, 2021.

115. Hua Y, Ding Y, Hou Y, Liu Y, Mao K, Cui Y and Nie H: Exosomal MicroRNA: Diagnostic marker and therapeutic tool for lung diseases. Curr Pharm Des 27: 2934-2942, 2021.

116. Minnis P, Kane R, Anglin R, Walsh S, Worrel J, Khan F, Lumsden RV, Whitty $S$ and Keane MP: Serum exosomes from IPF patients display a fibrotic. miRNA profile that correlates to clinical measures of disease severity. Eur Respir Rev 46 (Suppl 59): PA3845, 2015.

117. Makiguchi T, Yamada M, Yoshioka Y, Sugiura H, Koarai A Chiba S, Fujino N, Tojo Y, Ota C, Kubo H, et al: Serum extracellular vesicular miR-21-5p is a predictor of the prognosis in idiopathic pulmonary fibrosis. Respir Res 17: 110, 2016.

118. Lacedonia D, Scioscia G, Soccio P, Conese M, Catucci L, Palladino GP, Simone F, Quarato CMI, Di Gioia S, Rana R, et al: Downregulation of exosomal let-7d and miR-16 in idiopathic pulmonary fibrosis. BMC Pulm Med 21: 188, 2021.

119. Kuse N, Kamio K, Azuma A, Matsuda K, Inomata M, Usuki J, Morinaga A, Tanaka T, Kashiwada T, Atsumi K, et al: Exosome-derived microRNA-22 ameliorates. pulmonary fibrosis by regulating fibroblast-to-myofibroblast differentiation in vitro and in vivo. J Nippon Med Sch 87: 118-128, 2020.

120. Inomata M, Kamio K, Azuma A, Matsuda K, Usuki J, Morinaga A, Tanaka T, Kashiwada T, Atsumi K, Hayashi H, et al: Rictor-targeting exosomal microRNA-16 ameliorates lung fibrosis by inhibiting the mTORC2-SPARC axis. Exp Cell Res 398: 112416, 2021.

121. Vasse GF, Nizamoglu M, Heijink IH, Schlepütz M, van Rijn P, Thomas MJ, Burgess JK and Melgert BN: Macrophage-stroma interactions in fibrosis: Biochemical, biophysical, and cellular perspectives. J Pathol 254: 344-357, 2021.

122. Kishore A and Petrek M: Roles of macrophage polarization and macrophage-derived. miRNAs in pulmonary fibrosis. Front Immunol 12: 678457, 2021

123. Yao MY, Zhang WH, Ma WT, Liu QH, Xing LH and Zhao GF: MicroRNA-328 in. exosomes derived from M2 macrophages exerts a promotive effect on the progression of pulmonary fibrosis via FAM13A in a rat model. Exp Mol Med 51: 1-16, 2019.

124. Wang D, Hao C, Zhang L, Zhang J, Liu S, Li Y, Qu Y, Zhao Y, Huang R, Wei J and Yao W: Exosomal miR-125a-5p derived from silica-exposed. macrophages induces fibroblast transdifferentiation. Ecotoxicol Environ Saf 192: 110253, 2020

125. Guiot J, Cambier M, Boeckx A, Henket M, Nivelles O, Gester F, Louis E, Malaise M, Dequiedt F, Louis R, et al: Macrophage-derived exosomes attenuate fibrosis. in airway epithelial cells through delivery of antifibrotic miR-142-3p. Thorax 75: 870-881, 2020.

126. Cruz FF and Rocco PRM: The potential of mesenchymal stem cell therapy for chronic lung disease. Expert Rev Respir Med 14: 31-39, 2020

127. Yang S, Liu P, Jiang Y, Wang Z, Dai H and Wang C: Therapeutic applications of. mesenchymal stem cells in idiopathic pulmonary fibrosis. Front Cell Dev Biol 9: 639657, 2021.

128. Ntolios P, Manoloudi E, Tzouvelekis A, Bouros E, Steiropoulos P, Anevlavis S, Bouros D and Froudarakis M: Longitudinal outcomes of patients. Enrolled. in a phase Ib clinical trial of the adipose-derived stromal cells-stromal vascular fraction in idiopathic pulmonary fibrosis. Clin Respir J 12: 2084-2089, 2018.

129. Hade MD, Suire CN and Suo Z: Mesenchymal stem cell-derived exosomes: Applications in regenerative medicine. Cells 10: 1959,2021

130. Wan X, Chen S, Fang Y, Zuo W, Cui J and Xie S: Mesenchymal stem cell-derived. extracellular vesicles suppress the fibroblast proliferation by downregulating FZD6 expression in fibroblasts via micrRNA-29b-3p in idiopathic pulmonary fibrosis. J Cell Physiol 235: 8613-8625, 2020

131. Lei X, He N, Zhu L, Zhou M, Zhang K, Wang C, Huang H, Chen S, Li Y, Liu Q, et al: Mesenchymal stem cell-derived extracellular vesicles Attenuate radiation-induced lung injury via miRNA-214-3p. Antioxid Redox Signal 35: 849-862, 2021. 
132. Zhou J,Lin Y,Kang X,Liu Z,Zhang W and Xu F: MicroRNA-186 in extracellular vesicles. from bone marrow mesenchymal stem cells alleviates idiopathic pulmonary fibrosis via interaction with SOX4 and DKK1. Stem Cell Res Ther 12: 96, 2021.

133. Ibrahim A, Ibrahim A and Parimon T: Diagnostic and therapeutic applications of extracellular vesicles in interstitial lung diseases. Diagnostics (Basel) 11: 87, 2021.

134. Parimon T, Yao C, Habiel DM, Ge L, Bora SA, Brauer R, Evans CM, Xie T, Alonso-Valenteen F, Medina-Kauwe LK, et al: Syndecan-1 promotes lung fibrosis by. regulating epithelial reprogramming through extracellular vesicles. JCI Insight 4: e129359, 2019.

135. Feng Z, Zhou J, Liu Y, Xia R, Li Q, Yan L, Chen Q, Chen X, Jiang Y, Chao G, et al: Epithelium- and endothelium-derived exosomes regulate the. alveolar macrophages by targeting RGS1 mediated calcium signaling-dependent immune response. Cell Death Differ 28: 2238-2256, 2021.

136. Dinh PC, Paudel D, Brochu H, Popowski KD, Gracieux MC, Cores J, Huang K, Hensley MT, Harrell E, Vandergriff AC, et al: Inhalation of lung spheroid cell secretome and exosomes promotes lung repair in pulmonary fibrosis. Nat Commun 11: $1064,2020$.
137. Kadota T,FujitaY,Araya J,Watanabe N,Fujimoto S,KawamotoH, Minagawa S, Hara H, Ohtsuka T, Yamamoto Y, et al: Human bronchial epithelial cell-derived. Extracellular. vesicle therapy for pulmonary fibrosis via inhibition of TGF- $\beta$-WNT crosstalk. J Extracell Vesicles 10: e12124, 2021.

138. Liu Z, Yan J, Tong L, Liu S and Zhang Y: The role of exosomes from BALF in lung. disease. J Cell Physiol: Aug 13, 2021 (Epub ahead of print).

139. Tieu A, Hu K, Gnyra C, Montroy J, Fergusson DA, Allan DS, Stewart DJ, Thébaud B and Lalu MM: Mesenchymal stromal cell extracellular vesicles as. Therapy. for acute and chronic respiratory diseases: A meta-analysis. J Extracell Vesicles 10: e12141, 2021.

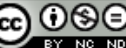

This work is licensed under a Creative Commons Attribution-NonCommercial-NoDerivatives 4.0 International (CC BY-NC-ND 4.0) License. 